and fibrosis in 1 patient, ventricular hypoperfusion in 2 pts and hypertrophic cardiomyopathy (HCM) in 2 pts. The pts with subepicardial inflamation and HCM had a more severe outcome. Three out of the 6 pts with cardiac involvement were pANCA (+). Hypereosinophilia was singnificantly higher in the group with cardiac involvement $(p<0.012)$. None of the patients had positive coronarography. Conclusions: Cardiac involvement is frecvent and is associated with hypereosinophilia. Absence of pANCA was not associated with the cardiac involvement, in contrast with other publications. CMR makes the difference between inflamatory and noninflamatory lesions, beeing useful in clinical assessment and in treatment decisions, therfore this examination could avoid a fatal outcome. Furthermore, in the future, CMR may replace cardiac byopsy.

References:

[1] Thomas Neumann Cardiac Involvement in Churg-Strauss Syndrome Impact of Endomyocarditis. Medicine (Baltimore). 2009 Jul;88(4):236-43.

[2] Nir Pillar, MD Hypereosinophilic Syndrome With Cardiac Involvement: Early Diagnosis by Cardiac Magnetic Resonance Imaging. Canadian Journal of Cardiology 28 (2012) 515.e11-515.e13.

Disclosure of Interest: None declared

DOI: 10.1136/annrheumdis-2017-eular.6383

\section{AB0558 BIOSIMILAR INFLIXIMAB FOR BEHÇET'S SYNDROME}

E. Dinçses ${ }^{1}$, S.N. Esatoğlu ${ }^{1}$, E. Seyahi ${ }^{1}$, M. Melikoğlu ${ }^{1}$, I. Fresko ${ }^{1}$, V. Hamuryudan ${ }^{1}$, D. Uçar ${ }^{2}$, Y. Özyazgan ${ }^{2}$, Z. Kutlubay ${ }^{3}$, C. Mat $^{3}$, S. Yurdakul ${ }^{1}$ G. Hatemi ${ }^{1} .{ }^{1}$ Internal Medicine, Division of Rheumatology; ${ }^{2}$ Department of Ophtalmology; ${ }^{3}$ Department of Dermatology, Istanbul University, Cerrahpasa Medical School, Istanbul, Turkey

Background: The efficacy and safety of biosimilar infliximab has been studied in several inflammatory conditions and biosimilar was approved for all indications of the reference product in several countries. However, to the best of our knowledge, there was no published reports on its use in Behçet's syndrome (BS).

Objectives: We aimed to report our experience with biosimilar infliximab for the treatment of 3 different types of organ involvements in BS.

Methods: We reviewed the charts of all BS patients who were prescribed infliximab in our multidisciplinary BS clinic. Among the 88 patients who were prescribed infliximab, 4 had used biosimilar infliximab $(5 \mathrm{mg} / \mathrm{kg})$ due to refractory disease despite conventional immunosuppressives.

Results: Case 1: The first patient was a 28-year-old man who had received azathioprine (AZA), cyclosporine-A and methotrexate for 6 years for ocular involvement. Six months after the immunosuppressives were stopped due to sustained remission he had a stroke with right hemiparesis. Cranial MRI revealed venous infarct extending from posterior limb of left internal capsule to pons and mesencephalon, involving corpus callosum. Cervical MRI revealed a hyperintense lesion between $\mathrm{C} 3-\mathrm{C} 8$ segments. His cranial MR venography excluded sinus thrombosis. He received intravenous pulse corticosteroid followed by biosimilar infliximab. He achieved clinical remission and his MRI at month 3 showed almost total regression of the lesions. He is still in remission at 7 th month of therapy. Case 2: The second patient was a 24-year-old man using AZA 2,5 $\mathrm{mg} / \mathrm{kg} /$ day for refractory skin lesions when he developed bilateral external iliac vein and right common iliac vein thrombosis. Biosimilar infliximab was added to AZA. His abdominal superficial collateral vein distension regressed and Doppler ultrasonography at month 4 showed recanalization in bilateral external iliac veins and residual thrombosis only in the right common iliac vein. Case 3 : The third patient was a 41-year-old man who had used colchicine, AZA, sulfasalazine, interferon-alpha and adalimumab for refractory arthritis. Biosimilar infliximab was started, with only a partial response. After one year treatment was switched to etanercept $50 \mathrm{mg} / \mathrm{week}$ and is attack-free for the last 7 months. Case 4: The fourth one was a 26-year-old man who was prescribed infliximab for panuveitis refractory to AZA, cyclosporine-A and interferon-alpha. The first infusion was biosimilar infliximab, but the following infusions were reference infliximab due to reimbursement policy of the hospital. There were no adverse events after switching to reference infliximab and the patient is doing well at 8 months of therapy.

Conclusions: Our limited experience showed that biosimilar infliximab may be effective for BS patients refractory to conventional immunosuppressives.

Disclosure of Interest: None declared

DOI: 10.1136/annrheumdis-2017-eular.6019

\section{AB0559 IMPROVING THE MANAGEMENT OF GIANT CELL ARTERITIS: A REVIEW OF CARE PATHWAY FOR PATIENTS WITH SUSPECTED GIANT CELL ARTERITIS IN A DISTRICT GENERAL HOSPITAL}

F.E. $\operatorname{Sin}^{1}$, M. Ragheb ${ }^{2}$, R. Shah ${ }^{2}$, A. Hunter ${ }^{2}$, W. Shattles ${ }^{2}$, U. Davies ${ }^{2}$, R. Makadsi ${ }^{2}$, S. Griffith2 ${ }^{1}{ }^{1}$ Rheumatology Department, Brighton and Sussex University Hospitals NHS Trust, Brighton; ${ }^{2}$ Rheumatology Department, East Surrey Hospital, Redhill, United Kingdom

Background: Giant cell arteritis (GCA) requires prompt diagnosis and treatment to prevent irreversible neuro-ophthalmic complications. Conversely, misdiagnosis leads to unnecessary treatment with high dose glucocorticosteroids (GC) and their associated complications. The British Society of Rheumatologists (BSR)
Guideline emphasises early recognition of symptoms and prompt treatment when index of clinical suspicion is high.

At East Surrey Hospital (ESH), we noted that some patients were not managed in accordance with BSR guidelines. Additionally, there is no existing care pathway for patients with suspected GCA to be referred to Rheumatology and for Temporal Artery Biopsy (TAB), often resulting in delayed care provision, or unnecessary use of healthcare resources.

Objectives: This study aims to audit the management of patients with suspected GCA against BSR guidelines. It also aims to evaluate patients' journey, to identify inefficiencies within the management pathway, in order to initiate improvements in service.

Methods: Case notes of patients seen in ESH with suspected GCA between March 2015 and December 2016 were reviewed retrospectively. Cases were identified through keyword search on hospital discharge letters and Rheumatology clinic letters.

Results: Case notes of 67 patients $(21 \mathrm{M}, 46 \mathrm{~F})$ were analysed. Of those presenting with suspected GCA, $31 \%$ fulfilled ACR classification criteria. $28 \%$ had documented visual symptoms at presentation.

Concordance with BSR guidelines: $79 \%$ of patients were started on GC at presentation. Of these $15 \%$ had a TAB within 7 days of starting GC. $34 \%$ were seen by a Rheumatologist within a week of presentation. Of those referred for a TAB $47 \%$ were performed within a week of referral.

Care Pathway: The majority of patients (78\%) first presented to GPs. Despite this, only $64 \%$ of referrals to rheumatology were by GPs. Other referral sources included the Acute Medical Unit (27\%) and ophthalmology (5\%). $49 \%$ were seen by a Rheumatologist within 7 days from referral. $25 \%$ had a final diagnosis of GCA.

Conclusions: The small proportion of patients with a final diagnosis of GCA highlighted that early Rheumatology assessment is important to minimise unnecessary TAB and high dose GC. Additionally, the lack of a structured care pathway and a standardised referral system for GCA meant that a large proportion of patients had delay in the diagnosis, inappropriate treatment with GC, and unnecessary TAB. These added to the burden of other already stretched medical specialities.

In light of this; a GCA pathway was implemented to enable rapid access to Rheumatology in patients with suspected GCA. The on-call team was advised to redirect any GP or A\&E referrals with suspected GCA to the rheumatology on-call bleep. Patients will be assessed and managed by the rheumatology on-call Registrar or Consultant within 24 hours. The impact of these new implementations will be reaudited in 2017 .

\section{References:}

[1] Bhaskar Dasgupta, Frances A. Borg, Nada Hassan, Leslie Alexander, Kevin Barraclough, Brian Bourke, Joan Fulcher, Jane Hollywood, Andrew Hutchings, Pat James, Valerie Kyle, Jennifer Nott, Michael Power, Ash Samanta; BSR and BHPR guidelines for the management of giant cell arteritis. Rheumatology 2010;49(8):1594-1597.

Disclosure of Interest: None declared

DOI: 10.1136/annrheumdis-2017-eular.5463

\section{AB0560 STUDY ON STREPTOCOCCAL INFECTION RELATIONSHIP WITH HENOCH-SCHONLEIN PURPURA IN CHILDREN}

F. Li ${ }^{1}, \mathrm{H}$. Zeng ${ }^{2} .{ }^{1}$ Department of Pediatric Allergy, Immunology and Rheumatolog; ${ }^{2}$ Department of Pediatric Allergy, Immunology and Rheumatology, Guangzhou Women and Children's Medical Center, Guangzhou, China

Objectives: To study hemolytic Streptococcus infection relationship with HenochSchonlein Purpura in children.

Methods: 42 cases in children with Henoch-Schonlein Purpura (Observer Group) and healthy children in 40 cases of physical examination (the control group) for blood antistreptolysin O (ASO) detection, observation group at the same time children are divided into (belly-non-abdominal Purpura and Purpura group set and repeatedly attacks groups and the Group of non-recurrent) for statistical analysis. Results: Observation group in the blood ASO detection positive 22 cases, accounted for 52.4\%; normal control group children 40 cases, blood ASO detection positive 2 cases, accounted for $5 \%$, both comparison differences has significantly significance $\left(x^{2}=22.22, p<0.01\right)$; abdominal type Purpura children with 23 cases, blood ASO detection positive 17 cases, accounted for $73.9 \%$; non-abdominal type Purpura children with 19 cases, blood ASO detection positive 5 cases, accounted for $26.3 \%$, both comparison differences has significantly significance $\left(x^{2}=9.45, p<0.01\right) ; 14$ cases in children with recurrent HenochSchonlein Purpura, ASO blood test positive in 12 cases, $85.7 \%$, non-recurrent attacks of 28 cases of children with Henoch-Schonlein Purpura, ASO blood test positive in 10 cases, $35.7 \%$, comparing the two differences are significant $\left(x^{2}=9.35, p<0.01\right)$.

Conclusions: Streptococcal infections may be the important factor relatated to Henoch-Schonlein Purpura in children.Purpura and Purpura of abdominal type recurrence is related with streptococcal infection, which is the great value to treatment.

Disclosure of Interest: None declared

DOI: 10.1136/annrheumdis-2017-eular.2136 